\title{
鄱阳湖碟形湖泊植物分解和水位变化对水体碳、氮浓度的叠加效应
}

\author{
张广帅 ${ }^{1,2}$, 于秀波 ${ }^{1,2 * *}$, 刘 宇 ${ }^{1}$, 张 欢 $^{3}$, 张全军 ${ }^{1,2}$, 李 雅 $^{1,2}$, 段后浪 ${ }^{1,2}$ \\ (1: 中国科学院地理科学与资源研究所中国科学院生态系统网络观测与模拟重点实验室, 北京 100101) \\ (2: 中国科学院大学,北京 100049) \\ (3:南昌大学生命科学学院,南昌 330031)
}

\begin{abstract}
摘 要: 以鄱阳湖典型碟形湖泊一一白沙湖为监测对象, 开展水体有机碳 $(\mathrm{TOC})$ 、总氮 $(\mathrm{TN})$ 、铵态氮 $\left(\mathrm{NH}_{4}^{+}-\mathrm{N}\right)$ 和硝态氮 $\left(\mathrm{NO}_{3}^{-}-\mathrm{N}\right)$ 浓度的年内动态变化的定位观测,结合在白沙湖开展的灰化䔔草 (Carex cinerascens) 分解模拟实验和稳定同位素 示踪技术, 对荎草分解过程和水体营养盐浓度变化进行时间匹配, 分析水体中颗粒态有机物 (POM) 的来源, 并探讨水位 变化和䔔草分解对水体营养盐浓度的交互作用. 结果表明, 水体 $\mathrm{TOC} 、 \mathrm{TN}$ 和 $\mathrm{NH}_{4}^{+}-\mathrm{N}$ 浓度在枯水季 $1-4$ 月明显高于其他 月份; 荳草在 $0 \sim 60 \mathrm{~d}$ 具有最高的分解速率, 鄱阳湖碟形湖泊洲滩湿地臺草分解起始时间为当年 12 月前后; 水体 POM 与 薹草活体和分解残体的 $\delta^{13} \mathrm{C}$ 差异不显著, 而与苦草和藻类具有显著性差异, 说明䔔草分解残体是水体中 POM 的主要来 源; 䔔草分解过程明显影响湖泊水体 $\mathrm{TN} 、 \mathrm{NH}_{4}^{+}-\mathrm{N}$ 和 TOC 浓度变化; 水位变化对湖泊水体 $\mathrm{NO}_{3}^{-}-\mathrm{N}$ 浓度变化效应最明显.

关键词: 分解;水位;水体营养盐;交互效应;稳定同位素;鄱阳湖;白沙湖;灰化菿草
\end{abstract}

\section{Accumulation effect of litter decomposition and water level on carbon and nitrogen in shal- low lake water of Lake Poyang}

ZHANG Guangshuai ${ }^{1,2}$, YU Xiubo ${ }^{1,2 * *}$, LIU Yu ${ }^{1}$, ZHANG Huan ${ }^{3}$, ZHANG Quanjun ${ }^{1,2}$, LI Ya ${ }^{1,2} \&$ DUAN Houlang ${ }^{1,2}$

(1: Key Laboratory of Ecosystem Network Observation and Modeling, Institute of Geographic Sciences and Natural Resources Research, Chinese Academy of Sciences, Beijing 100101, P.R.China)

(2: University of Chinese Academy of Sciences, Beijing 100049, P.R.China)

(3: College of Life Science, Nanchang University, Nanchang 330031, P.R.China)

Abstract: Water level, an important hydrological factor in shallow lakes, has great influence on chemical processes. Wetland plants have become an important means of ecological restoration, but the problem of producing pollution after the plant decaying has been paid extensive attention. Base on the observation of water nutrients concentration of Lake Baisha, the monthly changes of total organic carbon (TOC), total nitrogen (TN), ammonium nitrogen $\left(\mathrm{NH}_{4}^{+}-\mathrm{N}\right)$ and nitrate nitrogen $\left(\mathrm{NO}_{3}^{-}-\mathrm{N}\right)$ concentrations were analyzed. Stable isotope analysis was applied to track the major source for particulate organic matter ( POM) in the water. Combined with the decomposition simulation experiment performed in Lake Baisha, we revealed the specific time of the decomposition stage of Carex cinerascens in natural state, and studied the interaction effect of water level and decomposition process on water nutrients. Results showed that TOC, TN, $\mathrm{NH}_{4}^{+}-\mathrm{N}$ and $\mathrm{NO}_{3}^{-}-\mathrm{N}$ concentrations in lake water from Jan. to Apr. during the dry season were significantly higher than those during other periods. Carex cinerascens had the highest decay rate during the early 60 days. Under natural state, decomposition of Carex cinerascens begin at December according to the exponential decay model. $\delta^{13} \mathrm{C}$ value of water POM was similar to Carex cinerascens, while had significant differences with Vallisneria natans and alga. Litter decomposition had a certain effect on $\mathrm{TN}, \mathrm{NH}_{4}^{+}-\mathrm{N}$ and TOC concentrations in water. Water level had obvious effect on $\mathrm{NO}_{3}^{-}-\mathrm{N}$ concentration in water. While water level and litter decomposition had accumulation effects on $\mathrm{TN}$ and $\mathrm{NH}_{4}^{+}-\mathrm{N}$ concentrations.

* 国家自然科学基金项目 (41471088) 和地方合作项目 (鄱阳湖水生态综合模型研究及开发)联合资助. 2017-06-16 收稿;2017-08-18 收修改稿. 张广帅(1989 ), 男, 博士研究生;E-mail : zhanggs.15b@ igsnrr.ac.cn.

** 通信作者;E-mail:yuxb@ igsnrr.ac.cn. 
Keywords: Decomposition; water level; water nutrients; interaction; stable isotope; Lake Poyang; Lake Baisha; Carex cinerascens

湿地植物作为湿地生态系统的初级生产者, 维系着整个生态系统的结构、功能和稳定程度, 对湿地营养 物质循环和碳蓄积功能具有重要影响 ${ }^{[1]}$. 湿地植物在生长发育过程中, 可以从土壤和水体中吸收和富集氮、 磷等营养元素, 调节湿地生态系统的营养物质平衡, 降低富营养化风险 ${ }^{[2-3]}$. 湿地植物衰亡调落后的腐烂分 解过程会通过复杂的生物、物理、化学作用把植物同化固定的有机物转化为无机物,进而以营养盐的形式通 过地表径流和地下水输送到水体. 水生植物在腐解过程中会对水体产生明显的氮、磷污染 ${ }^{[4-6]}$. 关于湿地植 物分解的水质效应, 研究手段多以实验室模拟和控制实验为主 ${ }^{[7-9]}$, 而缺少对湿地生态系统的实地监测研究.

鄱阳湖是长江流域最大的通江湖泊, 在洪水调蓄和水质净化方面发挥着重要作用 ${ }^{[10]}$. 作为典型的季节 性湖泊, 它的水位每年都会发生有规律的季节性波动. 水位的波动是湖泊生态系统结构和功能的重要控制 因素 ${ }^{[11]}$, 不仅会影响湖泊湿地生物的生长、分布 ${ }^{[12]}$, 还会改变湖泊水化学过程, 对水体环境产生诸多方面的 影响 ${ }^{[13-14]}$. 在低水位阶段, 水体会普遍出现水质下降的现象 ${ }^{[15]}$, 在整个水文周期中,氮、磷等营养盐浓度和 水体叶绿素 $\mathrm{a}$ 浓度最高值均出现在低水位阶段 ${ }^{[16]}$. 受长江和 “五河” 双重影响, 鄱阳湖湖区水位 10 月后稳 定退水, 湖水落槽, 洲滩出露, 鄱阳湖周年内水位差可达 $7 \mathrm{~m}^{[17]}$. 出露的洲滩为丰富的湿地植物提供了有利 的生境. 因此在枯水期, 鄱阳湖的水质不仅受到水位的调控, 还会因为洲滩植物的分解作用发生改变. 灰化 薹草 (Carex cinerascens) 是鄱阳湖分布面积最大的植物群丛, 对鄱阳湖湿地生物地球化学循环具有重要作 用 ${ }^{[17]}$. 灰化䔔草生长过程具有明显的季节变化, 在整个洲滩出露期内有 2 个生长季, 秋季自 9 月洲滩出露水 面后开始萌发, 至 12 月枯萎; 从翌年 2 月开始进人春季生长期 ${ }^{[18]}$. 因此秋季莒草的分解过程为洲滩湿地生 态系统提供了稳定的碳源. 有鉴于此, 本文以鄱阳湖典型碟形子湖泊白沙湖为监测对象,结合灰化蕚草原位 分解实验和湖泊水位、水质监测数据研究了子湖尺度上水位变化和植物分解过程对枯水期水体碳、氮浓度 的叠加效应, 以期为完善鄱阳湖水质安全预警机制和草洲管理提供科学认识.

\section{1 材料与方法}

\section{1 研究区概况}

鄱阳湖 $\left(28^{\circ} 24^{\prime} \sim 29^{\circ} 46^{\prime} \mathrm{N}, 115^{\circ} 49^{\prime} \sim 116^{\circ} 46^{\prime} \mathrm{E}\right.$ ) 地处江西北部, 长江中下游, 南北相隔 $170 \mathrm{~km}$, 东西最大 跨度 $70 \mathrm{~km}$. 鄱阳湖属于东亚季风区, 为典型亚热带季风气候, 夏季炎热多雨, 冬季低温少雨, 年平均降水量 为 $1387 \sim 1795 \mathrm{~mm}$, 年内、年际变化较大. 年降水量最大为 $2452.8 \mathrm{~mm}$ (1954 年), 最小为 $1082.6 \mathrm{~mm}$ ( 1978 年), 最大 6 个月降水量 ( $3-8$ 月) 占全年降水量的 $74.4 \%$. 年平均蒸发量为 $800 \sim 1200 \mathrm{~mm}$, 约有一半集中在 温度最高的 7-9 月. 多年平均气温 $17.6^{\circ} \mathrm{C}$, 最冷月 ( 1 月) 平均气温 $5.1^{\circ} \mathrm{C}$, 最热月 ( 7 月) 平均气温 $29.5^{\circ} \mathrm{C}$. 受 鄱阳湖水文节律季节性变化的影响, 鄱阳湖湿地表现出典型的水陆相交错变化, 在鄱阳湖丰水期, 水位高, 湿地处于湖相淹水状态, 随着水位降低, 处在不同高程的洲滩湿地相继出露, 湿地植被开始发育, 呈现出河、 湖、滩交错的湿地景观格局. 分解模拟实验样地位于江西南矶湿地国家级自然保护区内的白沙湖,地处赣江 三角洲前缘, 属典型的内陆河口湿地区. 受鄱阳湖季节性周期水文变化影响, 保护区在 4-9 月除南山岛和 矶山岛外, 其余地方均被淹没, 10 月份湖水逐渐消退, 归人碟形洼地, 不同高程的洲滩相继出露, 呈现河、湖、 洲交错的状态, 使得该区域形成了大量土壤肥沃、水热充裕的泥滩和草洲. 白沙湖为典型的碟形湖泊,优势 植被为灰化荎草、南荻 (Triarrhena lutarioriparia)、芦苇( Phragmites australis)、曧草(Phalaris arundinacea) 等. 其中, 灰化薹草在南矶山保护区内集中连片大面积分布, 几乎遍及整个湿地洲滩, 盖度为 $85 \% \sim 100 \%{ }^{[17]}$.

\section{2 分解实验设计}

分解实验样地位于鄱阳湖湿地典型碟形子湖泊白沙湖 (图 1), 样地面积为 $200 \mathrm{~m} \times 300 \mathrm{~m}$, 样地内优势植 被为灰化䔔草, 伴生种为南荻和芦苇. 由于枯水期灰化蕚草在鄱阳湖草洲分布面积最广, 优势度最大, 因此 本研究选择灰化萄草为分解对象. 为了保证实验结果的可靠性, 按照地下水位将研究区样地划分为 4 个梯 度带 (表 1), 水位梯度带按照由湖岸到湖心的方向平行分布, 依次为 GT-A、GT-B、GT-C 和 GT-D (图 1), 梯度 带之间相隔约 $100 \mathrm{~m}$. 每个地下水位梯度带内根据微地形差异设置 3 6 个实验样点, 荎草分解实验样点共 
计 20 个, 每个样点处埋人细口径 (内径为 $2 \mathrm{~cm}$ ) PVC 管 (绕管壁等距离钻取 4 个内径约 $3.5 \mathrm{~mm}$ 的小孔, 埋人 地下约 $70 \mathrm{~cm}$, 用铅垂线保证管壁与水平面垂直) 用于测定地下水位,地下水位测量时间为 2011 年 10 月 15 日、11月 15 日、12 月 15 日和 2017 年 1 月 15 日,每日 9:00、13:00 和 16:00 各测量 1 次,测量方法为用钢卷 尺测量 PVC 管中水面与地表间的距离. 具体方法参见文献 [19].
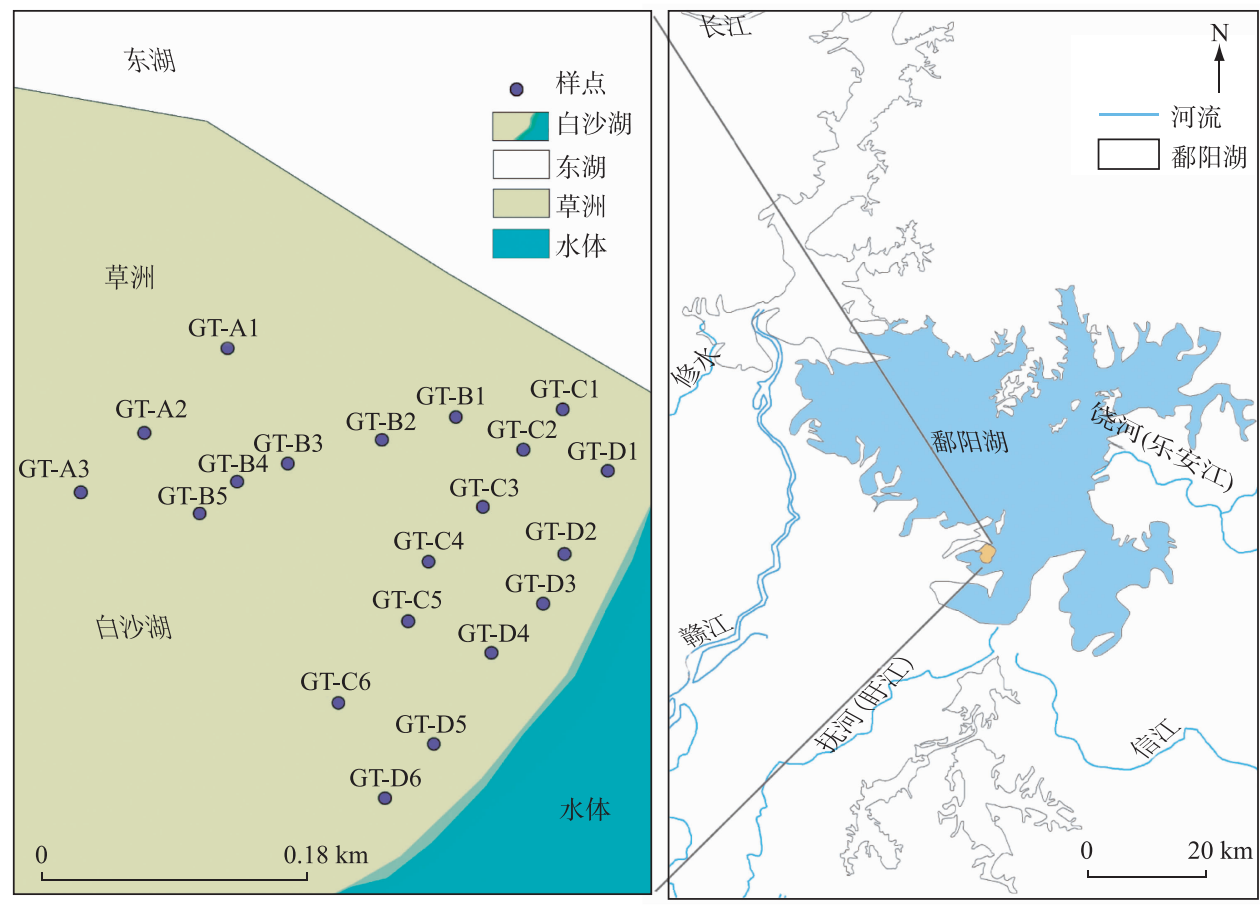

图 1 研究区地理位置与样地设置

Fig. 1 Location of the study area and sampling sites

表 1 采样点基本信息

Tab.1 Basic information of sampling sites

\begin{tabular}{crccc}
\hline 梯度带 & 生物量 $/\left(\mathrm{g} / \mathrm{m}^{2}\right)$ & 平均高度 $/ \mathrm{cm}$ & 平均盖度 $/ \%$ & 平均地下水位 $/ \mathrm{cm}$ \\
\hline GT-A & $153.33 \pm 67.39$ & $40.25 \pm 7.70$ & 51 & $-33.47 \pm-7.97$ \\
GT-B & $171.46 \pm 88.49$ & $29.55 \pm 2.36$ & 63 & $-21.54 \pm-3.18$ \\
GT-C & $70.05 \pm 14.13$ & $27.48 \pm 3.70$ & 42 & $-7.14 \pm-4.20$ \\
GT-D & $50.87 \pm 19.19$ & $12.88 \pm 9.02$ & 17 & $-0.70 \pm-2.66$ \\
\hline
\end{tabular}

植物分解实验采用尼龙网袋法. 为避免分解袋中植物残体的非分解损失, 同时保证不限制分解作用, 选 择了 100 目 $(0.15 \mathrm{~mm})$ 、规格为 $15 \mathrm{~cm} \times 15 \mathrm{~cm}$ 的网孔分解袋. 由于本文主要研究枯水期洲滩植物分解过程对 水体环境的影响, 因此在草洲上采集薹草成熟叶片进行实验, 采集时间为 2016 年 10 月 20 日. 叶片用去离子 水冲洗后, 剪成 $10 \mathrm{~cm}$ 长的小段, 置于 $60^{\circ} \mathrm{C}$ 烘箱中烘干至恒重, 每种植物类型单独装袋, 分别称取 $5.00 \mathrm{~g}$ 分 解样品装人尼龙网袋中. 将分解袋用竹竿固定在大样地的样点地表. 分解袋回收时间为实验开始后的第 15 、 $30 、 60 、 90 、 120$ 和 $180 \mathrm{~d}$. 因为水位上涨, 实验样地开始被水体淹没, 分解实验终止时间为 2017 年 4 月. 分解 袋带回实验室后, 清除表面杂物并用去离子水冲洗干净后置于 $60^{\circ} \mathrm{C}$ 烘箱中烘干至恒重, 测量其干物质质量、 纤维素含量和木质素含量. 纤维素和木质素含量的测定方法见文献 [20].

为了验证分解模拟实验的准确性, 同时根据天然分解状态下莒草枯落物残体纤维素、木质素残留含量 
确定洲滩荎草分解起始时间, 在实验样地 GT-A 和 GT-B 梯度带内设置 6 个薹草生长定位监测样方 (TC-1、 TC-2、TC-3、TC-4、TC-5 和 TC-6) ( $0.5 \mathrm{~m} \times 0.5 \mathrm{~m})$, 用于确定莒草的衰老时间(生物量不再增长). 于 2017 年 1 月 20 日采集 6 个样方内的荎草枯死物,烘干后测定其纤维素和木质素含量.

\section{3 湖泊水体颗粒态有机物 (POM) 来源测定}

水体中 POM 受外界环境影响显著, 能够反映水体环境与外界环境的关系, 因此测定湖泊水体中 POM 的稳定同位素 $\delta^{13} \mathrm{C}$ 和 $\delta^{15} \mathrm{~N}$ 比值, 通过同位素示踪技术确定其主要来源, 以建立枯水期水体环境质量与洲滩 植物分解的关系. 于 2017 年 2 月采集白沙湖表层水样,用 GF/F 玻璃纤维滤膜 (预先于 $450^{\circ} \mathrm{C}$ 烧 $4 \sim 6 \mathrm{~h}$ ) 收集 悬浮颗粒物. POM 的可能来源中, 薹草活体在水体附件的草洲上采集; 薹草分解残体样品由分解模拟实验提 供; 苦草样品在浅水区域采集, 附着藻类采集方法为用牙刷从沉水植被的叶片刮取, 并用 $1 \mathrm{~N}$ 盐酸溶液酸化 处理; POM 的提取方法为将水样先用 $25^{\#}$ 浮游生物网 (网径 $64 \mu \mathrm{m}$ ) 过滤, 然后将较纯净的水样再次过滤到预 烧 $\left(500^{\circ} \mathrm{C}, 2 \mathrm{~h}\right.$ ) 的玻璃纤维膜 (Whatman GF/F, $47 \mathrm{~mm}$ ) 上, 并用过量的 $1 \mathrm{~N}$ 盐酸溶液酸化处理. 所有稳定同 位素测试样品在 $60^{\circ} \mathrm{C}$ 烘 $48 \mathrm{~h}$, 然后均匀研磨, 放人干燥器中保存待测. 样品碳、氮稳定同位素采用美国 Thermo 公司的元素分析仪与 Delta Plus Finnigan MAT 253 同位素质谱仪测定,测定方法详见文献[21].

\section{4 湖泊水位水质测定}

2016 年 4 月 -2017 年 4 月每月 6 日左右采样 1 次,每次采样顺序一致,方法参照文献[22]. 监测项目有 湖泊水体的总有机碳 $(\mathrm{TOC})$ 、总氮 $(\mathrm{TN})$ 、铵态氮 $\left(\mathrm{NH}_{4}^{+}-\mathrm{N}\right)$ 和硝态氮 $\left(\mathrm{NO}_{3}^{-}-\mathrm{N}\right)$, 各类水质因子分析方法均参考 文献 [23]. 2016-2017 年水位数据由江西省鄱阳湖水文局提供.

\section{5 数据统计分析}

䔔草分解过程中纤维素和木质素衰减系数的计算公式为:

$$
\ln \frac{M_{t}}{M_{0}}=-k_{60} \cdot t
$$

式中, $M_{t}$ 为分解 $t$ 时间后的纤维素或木质素残留量, $M_{0}$ 为纤维素或木质素的初始含量, $t$ 为分解时间, $k$ 为平 均衰减系数. 由生物量随时间的衰减曲线可知, 研究区菫草物质降解最快的时间段为 $0 \sim 60 \mathrm{~d}$, 因此本研究选 择采用前 $60 \mathrm{~d}$ 的平均衰减系数 $\left(k_{60}\right)$ 来建立臺草枯死物自然分解状态和实验模拟状态的匹配关系.

采用 Microsoft Excel 2016 和 Origin lab Pro8 软件进行数据处理和制图,采用 R Studio 3.4.0 软件进行水 位和分解状态对水体碳、氮浓度的交互作用分析,交互作用水体营养盐数据为白沙湖水质数据.

\section{2 结果与分析}

\section{1 湖泊水体碳、氮浓度和水位的时间变化}

观测年内 $\left(2016\right.$ 年 4 月- 2017 年 4 月) 白沙湖水体数据进行统计分析 (图 2), TOC、TN 和 $\mathrm{NH}_{4}^{+}-\mathrm{N}$ 的浓度 均在 2017 年 1 月份开始升高, 且在之后的 3 个月内 $(1-3$ 月) 处在较高水平, 随着水位在 4 月开始抬升, TOC 和 $\mathrm{NH}_{4}^{+}-\mathrm{N}$ 浓度逐渐降低. 而 $\mathrm{NO}_{3}^{-}-\mathrm{N}$ 浓度在观测时间段内随时间变化不明显. 总体上水体营养盐浓度表 现为枯水期 $>$ 丰水期. 1 月为水体营养盐浓度变化的关键时间点. 2016 年 12 月 -2017 年 1 月湖泊水体 TOC、 $\mathrm{TN} 、 \mathrm{NH}_{4}^{+}-\mathrm{N}$ 和 $\mathrm{NO}_{3}^{-}-\mathrm{N}$ 浓度分别升高了 1.93、3.84、5.90 和 11.28 倍. 监测年内白沙湖水体 $\mathrm{TOC} 、 \mathrm{TN} 、 \mathrm{NH}_{4}^{+}-\mathrm{N}$ 和 $\mathrm{NO}_{3}^{-}-\mathrm{N}$ 的年平均浓度分别为 $11.85 、 3.72 、 0.57$ 和 $0.49 \mathrm{~g} / \mathrm{L}$. 水体 $\mathrm{TOC} 、 \mathrm{TN} 、 \mathrm{NH}_{4}^{+}-\mathrm{N}$ 浓度在 2017 年 1 月之前均 低于年平均浓度值,而在 2017 年 1 月- 2017 年 4 月高于年平均浓度值.

监测年内, 湖泊水位呈先升高后降低的趋势 (图 3), 最高值出现在 2016 年 7 月, 平均水位为 $20.39 \mathrm{~m}$, 最低值出现在 2017 年 1 月, 平均水位为 $12.40 \pm 0.41 \mathrm{~m}$. 监测年内全年平均水位为 $14.61 \pm 0.05 \mathrm{~m}$, 变异系数为 $0.20 \mathrm{~m}$, 而枯水期 (2016 年 10 月- 2017 年 3 月) 内湖泊平均水位为 $12.29 \pm 0.37 \mathrm{~m}$, 变异系数为 0.03 , 远低于 全年水位变异系数.

\section{2 洲滩湿地植物自然状态下分解初始时间}

分解袋内薹草生物量随分解时间递减 (图 4), 0 60 d 内生物量减少了 $32.87 \% \pm 4.29 \%, 60 \sim 180 \mathrm{~d}$ 生物 量变化缓慢,仅减少 $10.70 \% \pm 4.34 \%$. 纤维素和木质素残存量可以更加精确地定量表达植物分解过程的动态 变化. 随着分解时间的增长, 分解袋内薹草的纤维素和木质素含量在 $0 \sim 60 \mathrm{~d}$ 内快速衰减, $60 \mathrm{~d}$ 后逐渐趋于 

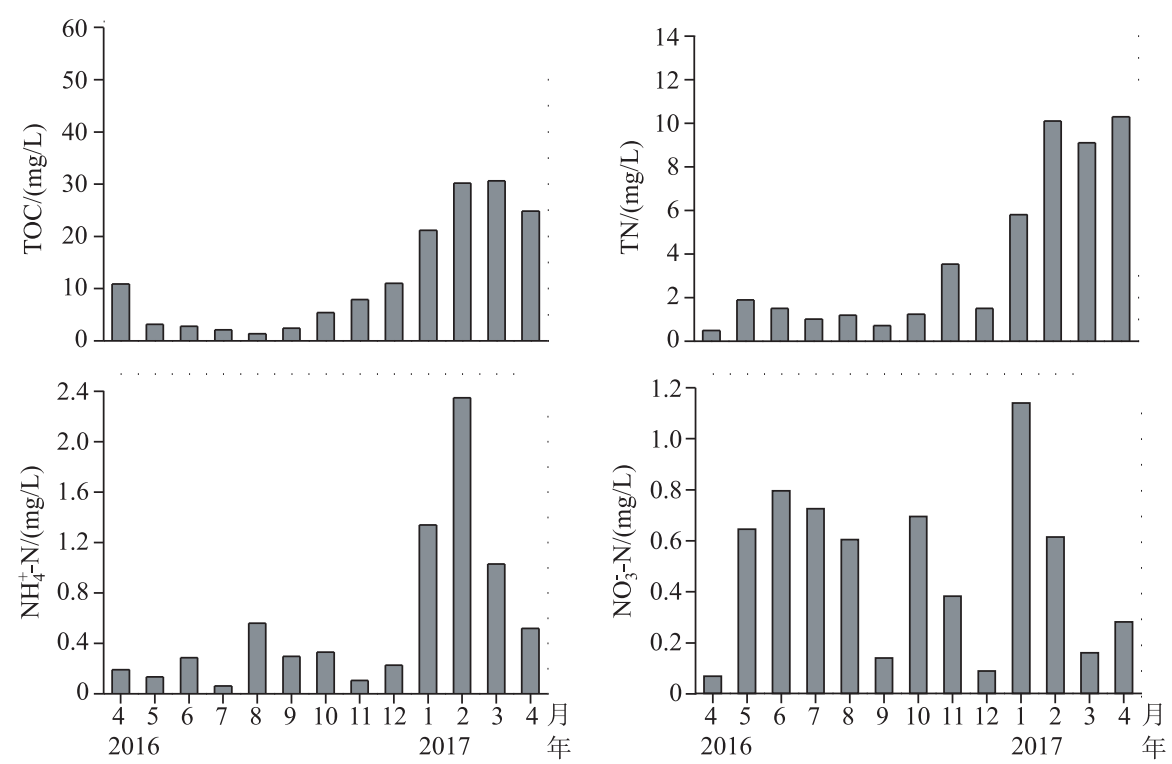

图 2 白沙湖水体总有机碳、总氮、铵态氮和硝态氮浓度随时间的变化

Fig.2 Monthly variation of TOC, TN, $\mathrm{NH}_{4}^{+}-\mathrm{N}$ and $\mathrm{NO}_{3}^{-}-\mathrm{N}$ in water of Lake Baisha

稳定. 分解 $60 \mathrm{~d}$ 后纤维素含量降低了 $46.17 \% \pm 6.28 \%$, 而木质素含量降低了 $39.96 \% \pm 11.50 \%$. 不同地下水 位梯度纤维素和木质素的衰减速度不同,在地下水位最高的梯度 GT-D, 纤维素和木质素均分解最快. 分解 残体碳、氮残留量随时间的变化不明显, 但是不同地下水位梯度间, GT-D 具有最低的碳、氮含量 (图 5).

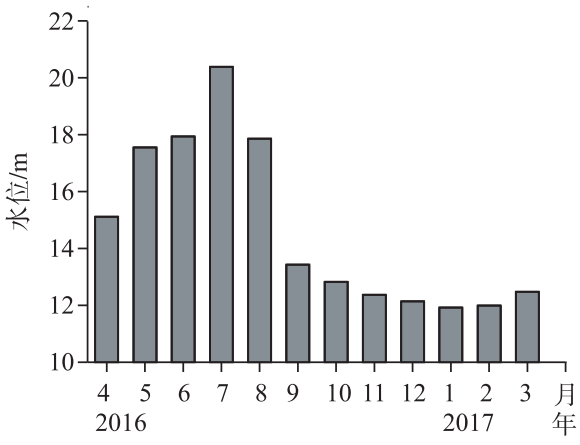

图 3 湖泊水位随时间的变化

Fig.3 Monthly variation of water level

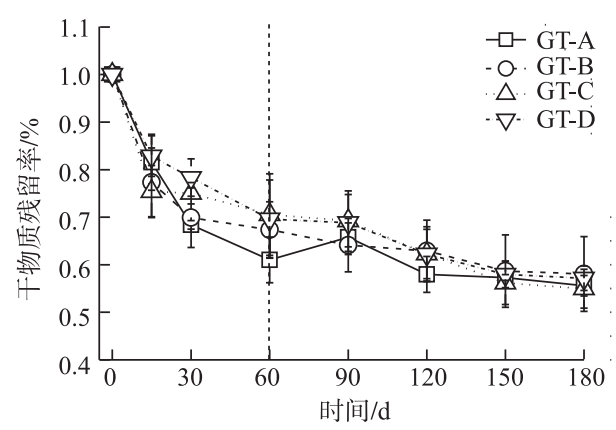

图 4 不同梯度带内植物枯死物中 干物质残留率的时间动态

Fig.4 Proportion of dry mass remaining in litter bags under different water table gradients

根据白沙湖分解模拟实验结果, 得到 $60 \mathrm{~d}$ 内 GT-A、GT-B、GT-C 和 GT-D 梯度带的纤维素平均衰减系数, 分别为 $1.00 \% 、 0.92 \% 、 1.32 \%$ 和 $1.44 \%$, 平均值为 $1.17 \%$; 木质素平均衰减系数分别为 $0.50 \% 、 0.60 \% 、 0.86 \%$ 和 $1.45 \%$, 平均值为 $0.85 \%$ 。由于自然状态下分解的天然枯死物样品取自高程相对较高、地下水位相对较低的 区域,所以采用 GT-A 和 GT-B 梯度带内纤维素和木质素的平均衰减系数作为估算其分解时间的参数. 1 月 20 日采集到的灰化蕚草自然分解状态下的枯死物样品中纤维素和木质素含量分别为 $9.92 \% \pm 1.87 \%$ 和 $7.96 \% \pm 0.45 \%$ (表 2). 由分解模拟实验可得 GT-A 和 GT-B 梯度带在 $60 \mathrm{~d}$ 内的纤维素平均衰减系数为 $0.96 \%$, 木质素平均衰减系数为 $0.55 \%$, 代人公式 (1) 可求得根据纤维素含量自然状态下灰化荎草枯死物分 
解时间为 $56.63 \pm 19.77 \mathrm{~d}$, 根据木质素含量自然状态下分解时间为 $74.20 \pm 10.58 \mathrm{~d}$, 综合可以判定截止到取样 时,取样点的灰化萄草枯死物自然分解时间约为 $60 \sim 80 \mathrm{~d}$,进而可以推算出天然枯死物取样点薹草衰老时间 为 $11-12$ 月之间.

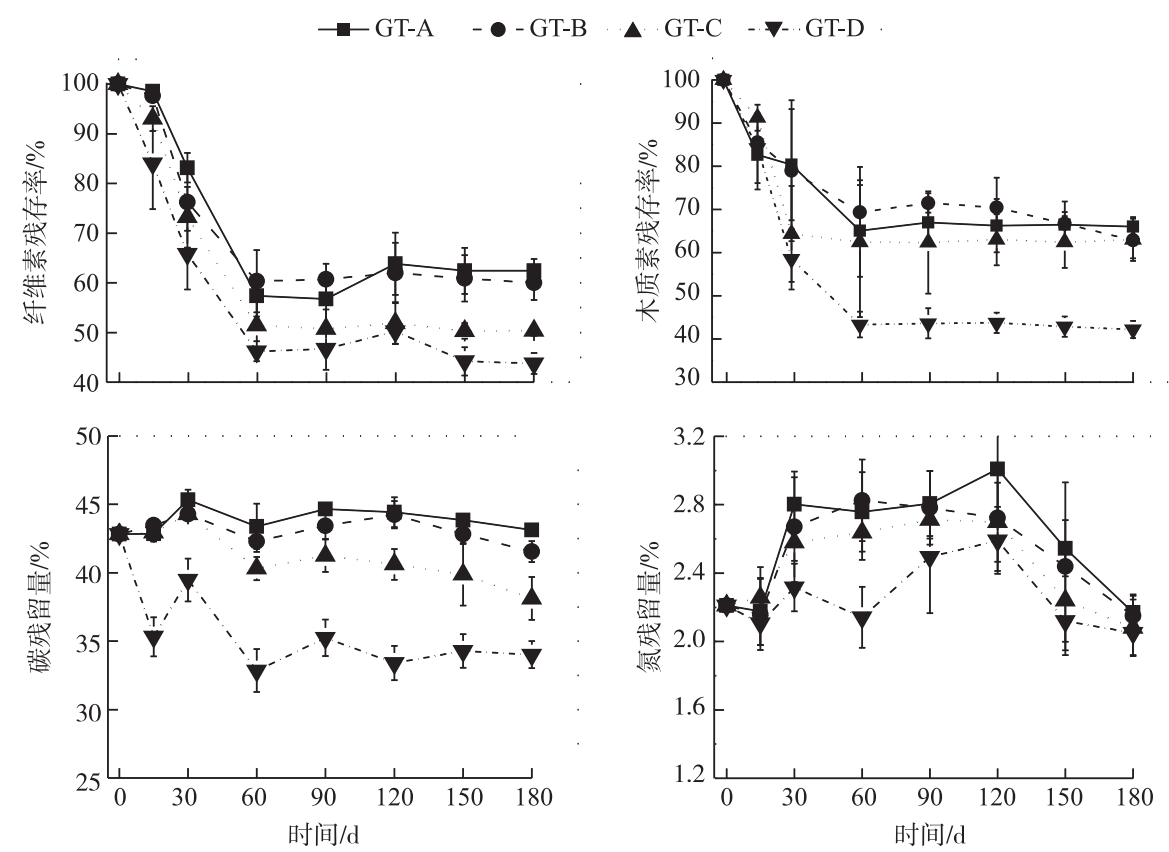

图 5 不同梯度带内植物枯死物中纤维素、木质素分解残存率及碳、氮残留量的时间动态

Fig.5 Proportion of initial cellulose \& lignin and carbon \& nitrogen remaining in litter bags under different water table gradients

表 2 自然状态下鄱阳湖灰化荎草枯死物中纤维素和木质素含量及分解时间估算”

Tab.2 Decomposition period estimation and cellulose \& lignin contents of Carex cinerascens under natural state of Lake Poyang

\begin{tabular}{ccccc}
\hline 样点 & 纤维素/\% & 木质素 $/ \%$ & $t_{\text {cellulose }} / \mathrm{d}$ & $t_{\text {lignin }} / \mathrm{d}$ \\
\hline TC-1 & 11.73 & 8.13 & 37.70 & 70.20 \\
TC-2 & 11.93 & 8.29 & 35.88 & 66.55 \\
TC-3 & 11.15 & 8.39 & 42.98 & 64.45 \\
TC-4 & 8.01 & 7.14 & 77.34 & 93.78 \\
TC-5 & 8.13 & 7.98 & 75.89 & 73.46 \\
TC-6 & 8.60 & 7.84 & 70.02 & 76.78 \\
平均值 & 9.92 & 7.96 & 56.63 & 74.20 \\
标准差 & 1.87 & 0.45 & 19.77 & 10.58 \\
变异系数 & 0.19 & 0.06 & 0.35 & 0.14 \\
\hline
\end{tabular}

* 取样时间为 2017 年 1 月 20 日; $t_{\text {cellulose }}$ 为根据纤维素含量确定的已分解时间; $t_{\operatorname{lignin}}$ 为根据木质素含量确定的已分解 时间.

研究表明湖泊洲滩低地的臺草秋季生长周期为 10-11 月 ${ }^{[24]}$, 所以由分解模拟实验所得平均衰减系数 推算出自然状态下莒草衰老时间与实际情况一致, 白沙湖分解模拟实验所得结果适用于鄱阳湖碟形湖泊洲 滩臺草在自然状态下的分解过程, 即碟形湖薹草群落分解过程起始于 11 月 15 日左右, 翌年的 $1-2$ 月左右 衰减速率处在较高水平, 营养释放能力最强. 


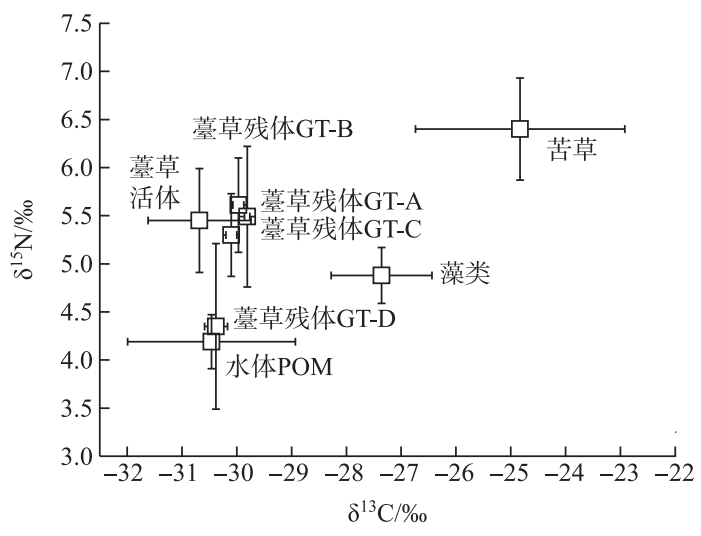

图 6 碟形湖水体颗粒态有机物、灰化臺草活体、 苦草、藻类及不同梯度带灰化薹草 分解残体的碳、氮稳定同位素比值

Fig. 6 Biplots of $\delta^{13} \mathrm{C}$ and $\delta^{15} \mathrm{~N}$ values of shallow lake water POM, living Carex cinerascens, Vallisneria natans, alga and residues of Carex cinerascens under different water table gradients

表 3 水位与分解状态对水体营养盐变化的交互效应

Tab.3 Effects of interaction of water level and decomposition state on water nutrients

\begin{tabular}{ccrl}
\hline 营养盐 & 参数 & 估计值 & $P$ \\
\hline $\mathrm{TOC}$ & 水位 & 0.33 & 0.81 \\
$\left(R^{2}=0.37, P=0.008\right)$ & 分解状态 & 66.13 & $0.06^{*}$ \\
& 水位:分解状态 & -4.05 & 0.12 \\
$\mathrm{TN}$ & 水位 & -0.06 & 0.88 \\
$\left(R^{2}=0.56, P<0.001\right)$ & 分解状态 & 22.55 & $0.03^{* *}$ \\
& 水位:分解状态 & -1.31 & $0.08^{*}$ \\
$\mathrm{NH}_{4}^{+}-\mathrm{N}$ & 水位 & -0.02 & 0.72 \\
$\left(R^{2}=0.53, P<0.001\right)$ & 分解状态 & 3.33 & 0.03 ** \\
& 水位:分解状态 & -2.00 & $0.08^{*}$ \\
$\mathrm{NO}_{3}^{-}-\mathrm{N}$ & 水位 & 0.09 & $0.04^{* *}$ \\
$\left(R^{2}=0.16, P=0.22\right)$ & 分解状态 & 0.93 & 0.41 \\
& 水位:分解状态 & -0.06 & 0.50 \\
\hline
\end{tabular}

$*$ 表示在 0.1 水平上具有显著效应, $* *$ 表示在 0.05 水平上 具有显著效应.

\section{3 碟形湖水体颗粒态有机物来源判定}

比较鄱阳湖碟形湖泊水体 POM 及其可能来 源的 $\delta^{13} \mathrm{C}$ 和 $\delta^{15} \mathrm{~N}$ 比值可知 (图 6), 水体 POM 的 $\delta^{13} \mathrm{C}$ 为 $-30.46 \% \%_{0} \pm 1.53 \%$, $\delta^{15} \mathrm{~N}$ 为 $4.19 \% 0 \pm 1.28 \%$, 与地下水位梯度最高区域 (GTD) 的薹草分解残体 数值最接近 $\left(\delta^{13} \mathrm{C}=-30.38 \% 0 \pm 0.21 \% 0, \delta^{15} \mathrm{~N}=\right.$ $4.34 \% 0 \pm 0.86 \% 0 ; P=1)$. 水体 POM 可能来源中, 苦 草的 $\delta^{13} \mathrm{C}$ 和 $\delta^{15} \mathrm{~N}$ 均与水体 POM 的 $\delta^{13} \mathrm{C}$ 和 $\delta^{15} \mathrm{~N}$ 具有极显著差异 $(P<0.01)$. 而浮游藻类的 $\delta^{13} \mathrm{C}$ 与 水体 POM 的 $\delta^{13} \mathrm{C}$ 具有极显著差异 $(P<0.01)$, $\delta^{15} \mathrm{~N}$ 差异不显著 $(P=0.98)$. 无论是菫草活体还是 菫草残体, 其 $\delta^{13} \mathrm{C}$ 和 $\delta^{15} \mathrm{~N}$ 与水体中 $\mathrm{POM}$ 的差异 均不显著 $(P>0.5)$.

\section{4 洲滩湿地植物分解及水位变化对水体碳、氮浓 度的影响}

根据分解模拟实验结果, 碟形子湖泊洲滩莒 草秋季分解过程起始于 11 月中旬, 分解状态一直 持续到翌年涨水 (4-5 月). 采用 “二值法” 对分解 状态进行赋值, 令 “ 1 ” 代表产生分解作用, “ 0 ” 代 表未产生分解作用, 则监测年内 2016 年 5 月、12 月以及 2017 年 1-4 月的分解状态赋值为 1 , 其余 月份分解状态赋值为 0 . 水位变化和植物分解状态 对白沙湖水体营养盐变化的交互效应分析结果表 明, 总体上水位和分解状态能够较好地预测白沙 湖水体 TOC、TN 和 $\mathrm{NH}_{4}^{+}-\mathrm{N}$ 浓度 $(P<0.01)$. 分解作 用的产生对白沙湖水体 $\mathrm{TN}$ 和 $\mathrm{NH}_{4}^{+}-\mathrm{N}$ 浓度变化具 有显著作用 $(P<0.05)$, 对 TOC 浓度变化具有一定 作用 $(P<0.1)$; 水位变化对水体 $\mathrm{NO}_{3}^{-}-\mathrm{N}$ 浓度变化具 有显著作用 $(P<0.05)$, 对 TOC、TN 和 $\mathrm{NH}_{4}^{+}-\mathrm{N}$ 浓度 变化无明显作用; 在 $\mathrm{TN}$ 和 $\mathrm{NH}_{4}^{+}-\mathrm{N}$ 浓度变化方面, 水位变化和分解过程具有一定程度的交互作用 $(P<0.1)($ 表 3$)$.

水位和分解状态对水体营养盐的交互作用图 （图 7) 直观表现了水体 TOC、 $\mathrm{TN} 、 \mathrm{NH}_{4}^{+}-\mathrm{N}$ 和 $\mathrm{NO}_{3}^{-}-\mathrm{N}$ 浓度随水位和分解状态的变化趋势. 根据分解作 用产生 $(\mathrm{DC}=0)$ 和不产生 $(\mathrm{DC}=1) 2$ 种条件下水体 营养盐变化特点, 对分解作用的不同强度下水体 营养盐对水位变化的响应进行模拟,可知 $\mathrm{DC}$ 为 0 时, $\mathrm{TOC} 、 \mathrm{TN}$ 和 $\mathrm{NH}_{4}^{+}-\mathrm{N}$ 浓度对水位变化的响应较弱, 随着 表征分解作用的 DC 值逐渐变大, TOC、 $\mathrm{TN}$ 和 $\mathrm{NH}_{4}^{+}-\mathrm{N}$ 浓度对水位变化的响应逐渐增强, 且随着水位的升高而 降低. 而 $\mathrm{NO}_{3}^{-}-\mathrm{N}$ 浓度与水位的关系没有受到分解作用的影响.

\section{3 讨论}

\section{1 水体营养盐浓度变化}

鄱阳湖碟形湖泊水体 $\mathrm{TN} 、 \mathrm{NH}_{4}^{+}-\mathrm{N}$ 和 $\mathrm{NO}_{3}^{-}-\mathrm{N}$ 浓度随时间的变化与主湖区一致, 枯水期大于丰水期, 营养 

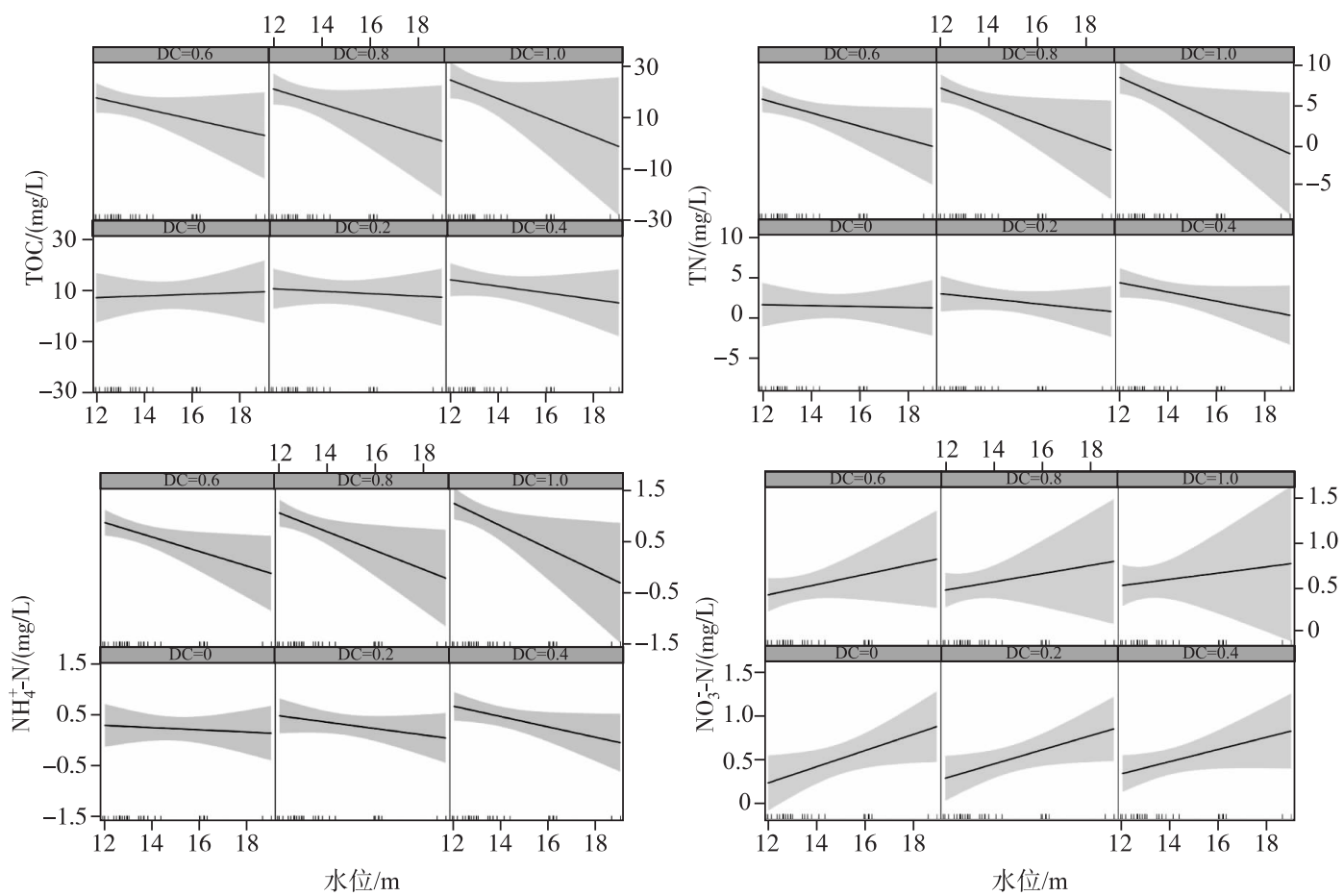

图 7 水位和分解状态对湖泊水体营养盐的交互作用 (DC 表示分解状态: $\mathrm{DC}=0$, 表示未发生分解; $\mathrm{DC}=1$, 表示发生分解; DC 在 $0 \sim 1$ 之间的数值 $(0.2 、 0.4 、 0.6$ 和 0.8$)$

为模型模拟的数值, 表示分解作用对水体营养盐的作用强度)

Fig.7 Interaction effects of water level and decomposition state on water nutrients

盐浓度随着湖泊水位的升高而降低 ${ }^{[13]}$. 随着湖泊水位上升, 子湖与大湖逐渐连成一体, 水环境容纳量增大, 悬浮物及营养盐浓度降低 ${ }^{[25]}$. 尽管 7-8 月水温升高, 湖泊营养盐内源释放增强, 但是夏季高水位对营养盐 具有稀释作用 ${ }^{[26]}$, 所以水体营养盐最低浓度均出现在 7-8 月. 但是研究表明在鄱阳湖主湖水体, TOC 浓度 并未表现出显著的季节差异,水位变化对水体 TOC 浓度分布影响较小 ${ }^{[27]}$, 但是本研究对典型碟形子湖白沙 湖的监测发现, 湖泊水体 $\mathrm{TOC}$ 与 $\mathrm{TN} 、 \mathrm{NH}_{4}^{+}-\mathrm{N}$ 浓度一样表现出枯水期高于丰水期的规律. 对于主湖, 由于 11 、 12 月水位偏低, 湖泊底泥上涌, 营养盐释放进人水体, 导致水体氮、磷等浓度升高, 水质降低 ${ }^{[28]}$. 但是碟形子 湖泊由于闸控作用,枯水期水位相对稳定, 12 月到翌年 3 月碟形湖泊水位维持在 $12.29 \mathrm{~m}$ 左右, 月间平均变 异系数仅为 0.03 , 而 $\mathrm{TOC} 、 \mathrm{TN} 、 \mathrm{NH}_{4}^{+}-\mathrm{N}$ 和 $\mathrm{NO}_{3}^{-}-\mathrm{N}$ 浓度在 12 月至翌年 3 月间均表现出先升高后降低的趋势, 这 一趋势可能与洲滩湿地植物分解过程中营养盐的释放和土壤淋溶有关. 诸多研究表明, 湿地植物腐烂分解 过程中, 会向水体释放大量营养盐, 快速的淋溶分解使水体营养盐水平短期内上升, 之后由于分解过程趋于 稳定,水体中氮、磷经生物和物理化学作用迅速减少 ${ }^{[8,29]}$.

\section{2 洲滩植物分解过程}

薹草分解模拟实验表明,在分解过程中,生物量、纤维素和木质素均在短时间内 $(0 \sim 60 \mathrm{~d})$ 迅速衰减,之 后逐步趋于稳定, 说明在分解初期其营养盐的释放能力最强. 与多数湿地植物分解过程一致, 臺草在分解过 程中呈现出明显的 2 个阶段: 快速淋溶阶段和缓慢分解阶段 ${ }^{[30]}$. 许多研究表明植物组织分解过程中衰减系 数并不恒定, 随着时间逐渐减小. 分解初期物质的迅速衰减主要取决于可溶性有机物的快速淋溶 ${ }^{[31]}$. 本研 究中木质素和纤维素在分解初期就以较高的衰减速度迅速减少, 其主要原因是湖泊草洲湿地上水分充足, 干湿交替现象频繁,微生物对分解底物的利用更加充分 ${ }^{[32]}$.

由于植物分解过程中碳、氮含量受分解者影响较大, 分解者为了维持自身生长, 必须从 $\mathrm{C} / \mathrm{N}$ 较低的环境 
中 (土壤、降水等) 吸取养分, 合成自身有机体使分解残体碳、氮含量发生改变 ${ }^{[33]}$. 很多研究都发现在植物分 解过程中碳、氮含量并不随时间呈有规则的指数衰减趋势 ${ }^{[34]}$, 本研究结果与其一致. 因此选择纤维素和木 质素含量建立指数衰减模型确定碟形子湖灰化荎草的衰减系数, 相对于碳、氮等指标更能真实反映客观情 况. 本研究也表明不同地下水位梯度带纤维素和木质素分解差异显著. 根据䓟草分解模拟实验确定纤维素 在碟形湖泊洲滩不同地下水位梯度带的平均衰减系数为 $1.00 \% 、 0.92 \% 、 1.32 \%$ 和 $1.44 \%$ (按地下水位梯度从 低到高排列), 木质素的平均衰减系数为 $0.50 \% 、 0.60 \% 、 0.86 \%$ 和 $1.45 \%$, 不同地下水位梯度带间的差异性主 要是因为分解微环境中 $\mathrm{pH}$ 、土壤含水量、土壤颗粒组成以及所调控的土壤微生物群落结构不同所造成 的 ${ }^{[35]}$. 根据地下水位梯度较低的 GT-A 和 GT-B 薹草纤维素和木质素平均衰减系数和莒草自然状态下分解 残留物中纤维素木质素残留量得到自然状态下蓋草分解时间为 $60 \sim 80 \mathrm{~d}$, 与荎草的实际生长周期和分解状 况一致 ${ }^{[24]}$, 一方面说明野外分解模拟实验结果科学可靠, 另一方面说明 12 月至翌年 1 月左右为洲滩莒草 群落养分释放能力最强的时间段, 与鄱阳湖碟形湖泊水体营养盐浓度高值出现的时间段相同.

\section{3 分解过程和水位对碟形湖泊水体营养盐浓度的叠加效应}

湖泊水体中 TOC 浓度与湖泊营养水平密切相关 ${ }^{[36]}$, 研究表明, 与可溶性有机碳相比, 颗粒态有机碳受 外界环境影响更大 ${ }^{[37]}$. 在太湖的研究发现湖泊水体中 POM 的 $\delta^{13} \mathrm{C}$ 与水生植物风眼莲比较接近 ${ }^{[21]}$. 本研究 中, 鄱阳湖碟形湖水体中 $\mathrm{POM}$ 的 $\delta^{13} \mathrm{C}$ 和 $\delta^{14} \mathrm{~N}$ 与荎草 (活体和分解残体) 差异性均不显著, 而且与距离水体 最近、地下水位梯度最高的薹草分解残体相似度最高, 说明洲滩植被, 尤其是臺草群落是枯水期湖泊水体 POM 的主要来源, 水体 POM 与洲滩植被的分解有密切关系. 碟形湖泊湿地洲滩植物在腐烂分解过程中, 会 向周围环境 (土壤、水体) 中释放大量营养盐 ${ }^{[5]}$, 研究表明湿地中泥沼的无机氮浓度显著高于高滩和岗地, 高 水分导致无机营养盐强烈淋溶, 进而在地表径流和地下水的作用下汇人水体, 使水体的营养盐浓度升高 ${ }^{[38]}$. 本研究中分解状态对水体 $\mathrm{TN}$ 和 $\mathrm{NH}_{4}^{+}-\mathrm{N}$ 浓度的效应最显著, 其次为 TOC 浓度, 因为在植物分解过程中会释 放大量的 TOC 和 TN 进人水体. 谢理等研究发现芦苇在死后可向周围释放大量营养盐 ${ }^{[29]}$. 由于进人水体中 的营养盐尤其是氮素会在水中微生物的作用下进行硝化和反硝化作用, 生成气体溢出, 因此植物分解营养 盐释放对水质的影响具有时效性. 丰水期水体营养盐浓度变化主要是因为水位较高, 水位下降过程中, 一定 程度上影响了水体营养盐浓度, 但是在碟形湖, 由于水位最低控制在 $12 \mathrm{~m}$ 左右, 因此枯水期水体营养盐浓 度取决于其输人的方式, 由于所研究的碟形子湖位于南矶湿地国家级自然保护区和鄱阳湖国家级自然保护 区核心区, 受外界人类活动干扰程度小, 而碟形湖泊洲滩植被覆盖度高, 尤其是臺草群落生物量最大, 这些 洲滩植被成为枯水期碟形湖水体营养盐的主要来源. 水体中的 $\mathrm{TN}$ 和 $\mathrm{NH}_{4}^{+}-\mathrm{N}$ 浓度均在分解过程最显著的 12 月至翌年 1 月份显著升高. 研究表明, 枯水期高植被覆盖区附近的水体要比中植被覆盖区和低植被覆盖区 附近的水体含有更高的 $\mathrm{TN}$ 和 $\mathrm{NH}_{4}^{+}-\mathrm{N}$ 浓度 ${ }^{[39]}$. 总体上水位改变了水体的环境容量, 而枯水期植物分解过程 则影响了碟形湖水体营养物质的输人. 通过分解模拟实验和天然分解过程的对照匹配可知, 碟形湖水体营 养盐浓度最高的月份与湿地植物分解最快的时间重叠, 进一步验证了分解对水体营养盐浓度变化的作用.

本研究仅根据洲滩植物分解的产生时间和水体中 POM 来源确定其对水体营养盐的生态效应, 为碟形 湖泊水质变化的认识提供新的角度和思路, 在以后的研究中可以运用同位素示踪的方法建立枯水期洲滩植 被分解过程和湖泊水体营养盐变化的定量关系, 从而进一步明确分解过程对水体营养盐的作用机理.

\section{4 结论}

1) 鄱阳碟形子湖白沙湖水体 $\mathrm{TOC} 、 \mathrm{TN} 、 \mathrm{NH}_{4}^{+}-\mathrm{N}$ 浓度在枯水期显著高于丰水期, 进人 1 月开始迅速升高, $\mathrm{TOC} 、 \mathrm{TN} 、 \mathrm{NH}_{4}^{+}-\mathrm{N}$ 浓度年内最高值出现在 $1-4$ 月.

2) 碟形湖洲滩灰化菿草在前 $60 \mathrm{~d}$ 分解最快, 纤维素和木质素的平均衰减系数为 $1.17 \%$ 和 $0.85 \%$. 根据 指数衰减模型, 确定碟形湖泊洲滩湿地洜草分解起始时间为当年 12 月前后, 在 12 月至翌年 1 月分解速度最 快,与湖泊水体营养盐浓度升高在时间上具有前后关联性.

3) 碟形湖泊中水体颗粒态有机物的 $\delta^{13} \mathrm{C}$ 为 $-30.46 \% 0 \pm 1.53 \% 0, \delta^{15} \mathrm{~N}$ 为 $4.19 \% 0 \pm 1.28 \%$, 与地下水位梯度 最高区域的薹草分解残体数值最接近, 而与苦草和藻类差异显著, 说明蕚草分解残体是湖泊水体颗粒态有 机物的主要来源, 进一步证明了洲滩植物分解是碟形湖泊水体营养盐在枯水期升高的主要原因. 
4) 分解作用和水位变化对碟形湖泊水体营养盐浓度存在交互叠加效应. 分解作用的产生对湖泊水体 $\mathrm{TN}$ 和 $\mathrm{NH}_{4}^{+}-\mathrm{N}$ 浓度的变化具有显著作用, 对 $\mathrm{TOC}$ 浓度变化具有一定作用; 水位变化对湖泊水体 $\mathrm{NO}_{3}^{-}-\mathrm{N}$ 浓度 变化具有显著影响; 在 $\mathrm{TN}$ 和 $\mathrm{NH}_{4}^{+}-\mathrm{N}$ 浓度变化方面, 水位变化和分解过程具有一定程度的交互作用. 通过模 型模拟,发现碟形湖泊水体 TOC、TN 和 $\mathrm{NH}_{4}^{+}-\mathrm{N}$ 浓度对水位变化的响应受到洲滩植物分解作用的影响.

\section{5 参考文献}

[ 1 ] Gronk JK, Fennessy MS eds. Wetland plants: Biology and ecology. Florida: CRC Press LLC, 2001.

[ 2 ] Li D, Huang D, Guo C et al. Multivariate statistical analysis of temporal-spatial variations in water quality of a constructed wetland purification system in a typical park in Beijing, China. Environmental Monitoring \& Assessment, 2015, 187 (1) : 4219.

[ 3 ] ZhouY, Han YG, Zhang M et al. Purification efficiency of four different ecotypes of wetland plants on eutrophic water body. Chinese Journal of Applied Ecology, 2016, 27(10): 3353-3360. [周玥, 韩玉国, 张梦等. 4 种不同生活型湿地 植物对富营养化水体的净化效果. 应用生态学报, 2016, 27(10): 3353-3360.]

[ 4 ] Yang WB, Wang GX, Wang G. Experimental study over the continuous effects of decaying Potamogeton crispus on water quality. Journal of Safety \& Environment, 2010, 10(2) : 90-92.

[ 5 ] Tang JY, Cao PP, Xu C et al. Effects of aquatic plants during their decay and decomposition on water quality. Chinese Journal of Applied Ecology, 2013, 24(1) : 83-89. [唐金艳, 曹培培, 徐驰等. 水生植物腐烂分解对水质的影响. 应 用生态学报, 2013, 24(1): 83-89.]

[ 6 ] Lu SY, Zhang PY, Xu G et al. The contaminants release rule of Zizania caduciflora, Phragmites austrails and Eichhornia crassipes. China Environmental Science, 2005, 25(5): 554-557. [卢少勇, 张彭义, 余刚等. 荠草、芦苇和水葫芦的污 染物释放规律研究. 中国环境科学, 2005, 25(5): 554-557.]

[ 7 ] Zhou LF, Zhao YY, Guan XT. The indoor simulation study on change of physical and chemical indicators of water quality during decomposition process of six kinds of aquatic plants. Wetland Science, 2016, 14(6): 832-839. [周林飞, 赵言稳, 关秀婷. 6 种水生植物腐烂过程中水质理化指标的变化室内模拟研究. 湿地科学, 2016, 14(6): 832-839.]

[ 8 ] Qi MX, Wang HP, Chen JD. Decomposition of Phragmites australis and Typha angustifolia and their effects on the water quality in winter and spring. J Lake Sci, 2017, 29(2) : 420-429. DOI: 10.18307/2017.0218. [戚美侠, 王红萍, 陈杰 冬. 春季芦苇 (Phragmites australis) 和狭叶香蒲 (Typha angustifolia) 的腐解过程及其对水质的影响. 湖泊科学, 2017, 29(2): 420-429.]

[ 9 ] Wu S, He S, Huang J et al. Decomposition of emergent aquatic plant (cattail) litter under different conditions and the influence on water quality. Water Air \& Soil Pollution, 2017, 228(2): 70.

[10] Zhao QG, Huang GQ, Qian HY. Ecological environment and sustainable development of Poyang Lake. Acta Pedologica Sinica, 2007, 44(2) : 318-326. [ 赵其国, 黄国勤, 钱海燕. 鄱阳湖生态环境与可持续发展. 土壤学报, 2007,44 (2) : 318-326.]

[11] Leira M, Cantonati M. Effects of water-level fluctuations on lakes: an annotated bibliography. Hydrobiologia, 2008,613 : 171-184.

[12] Wantzen KM, Rothhaupt KO, Mrtl M et al. Ecological effects of water-level fluctuations in lakes: an urgent issue. Hydrobiologia, 2008, 613: 1-4.

[13] Hu ML, Wu ZQ, Liu YL. Characteristic of water level and its effects on water environmental factors in Hukou area of Poyang Lake. Journal of Hydroecology, 2010, 3(1): 1-6. [胡茂林, 吴志强, 刘引兰. 鄱阳湖湖口水位特性及其对水环 境的影响. 水生态学杂志, $2010,3(1): 1-6$.

[14] Ding QZ, Liu XQ, Zhang XK. Impacts of water level fluctuations on substrate environments of lakeshore zone of the lakes in the middle and lower reaches of the Yangtze River. J Lake Sci, 2014, 26(3) : 340-348. DOI: 10.18307/2014.0302. [丁庆章, 刘学勤, 张晓可. 水位波动对长江中下游湖泊湖滨带底质环境的影响. 湖泊科学, 2014, 26(3): 340-348.]

[15] Wu QX, Han GL, Tang Y. Effect of water level fluctuation on ecological environment of Lake/ Reservoir riparian zone: A review. Earth and Environment, 2009, 37(4): 446-453. [ 吴起金金, 韩贵琳, 唐杨. 水位变化对湖泊(水库) 消落带生 态环境影响的研究进展. 地球与环境, 2009, 37(4) : 446-453.] 
[16] Liu X, Liu BG, Chen YW et al. Responses of nutrients and chlorophyll a to water level fluctuations in Poyang Lake. Environmental Science, 2016, 37(6) : 2141-2148. [刘霞, 刘宝贵, 陈宇炜等. 鄱阳湖浮游植物叶绿素 a 及营养盐浓度对 水位波动的响应. 环境科学, 2016, 37(6): 2141-2148.]

[17] Hu ZP, Ge G, Liu CL et al. Structure of Poyang Lake wetland plants ecosystem and influence of lake water level for the structure. Resources and Environment in the Yangtze Basin, 2010, 19(6): 597-605. [胡振鹏, 葛刚, 刘成林等. 鄱阳湖 湿地植物生态系统结构及湖水位对其影响研究. 长江流域资源与环境, 2010, 19(6): 597-605.]

[18] Wu Q, Yao B, Zhu LL et al. Seasonal variation in plant biomass of Carex cinerascens and its carbon fixation assessment in a typical Poyang Lake marshland. Resources and Environment in the Yangtze Basin, 2012, 21(2): 215-219. [吴琴, 尧 波, 朱丽丽等. 鄱阳湖典型菫草湿地生物量季节变化及固碳功能评价. 长江流域资源与环境, 2012, 21(2): 215-219.]

[19] Li L, Lei GC, Gao JQ et al. Effect of water table and soil water content on methane emission flux at Carex muliensis marshes in Zoig(e) Plateau. Wetland Science, 2011, 9(2): 173-178. [李丽, 雷光春, 高俊琴等. 地下水位和土壤含水量 对若尔盖木里菫草沼泽甲烷排放通量的影响. 湿地科学, 2011, 9(2) : 173-178.]

[20] Ziegler F, Kögel I, Zech W. Alteration of gymnosperm and angiosperm lignin during decomposition in forest humus layers. Journal of Plant Nutrition \& Soil Science, 1986, 149(3): 323-331.

[21] Wen ZR, Xu J, Xie P. Carbon and nitrogen stable isotopes of macrophytes from Lake Taihu. J Lake Sci, 2016, 28 (1) : 163-169. DOI: 10.18307/2016.0119. [温周瑞, 徐军, 谢平. 太湖高等水生植物稳定碳、氮同位素特征. 湖泊科学, 2016, 28(1): 163-169.

[22] Nanjing Institute of Geography and Limnology, Chinese Academy of Sciences ed. Technical regulations for lake investigation. Beijing: Science Press, 2015: 2-4. [中国科学院南京地理与湖泊研究所. 湖泊调查技术规程. 北京: 科学出版 社, 2015: 2-4.]

[23] "Water and wastewater monitoring and analysis method" editorial board of State Environmental Protection Administration of China ed. Monitoring and analysis methods of water and wastewater: fourth edition. Beijing: China Environmental Science Press, 2002. [ 国家环境保护总局《水和废水监测分析方法》编委会. 水和废水监测分析方法: 第 4 版. 北京: 中国 环境科学出版社, 2002.]

[24] Guan L, Wen L, Feng D et al. Delayed flood recession in central Yangtze floodplains can cause significant food shortages for wintering geese: results of inundation experiment. Environmental Management, 2014, 54(6) : 1331.

[25] Zhang YL, Qin BQ, Chen WM et al. A study on total suspended matter in Lake Taihu. Resources and Environment in the Yangtze Basin, 2004, 13(3): 266-271. [张运林, 秦伯强, 陈伟民等. 太湖水体中悬浮物研究. 长江流域资源与环 境, 2004, 13(3): 266-271.]

[26] Zeng HA, Wu JL. Characteristics and mechanisms of water environmental changes in the lakes along the middle and lower reaches of Yangtze River. Advance in Water Science, 2007, 18(6): 834-841. [曾海鳌, 吴敬禄. 长江中下游不同营养 水平湖泊水体环境变化特征及机制. 水科学进展, 2007, 18(6):834-841.]

[27] Liu QC, Yu C, Zhang J. Water quality variations in Poyang Lake. Journal of Agro-Environment Science, 2013, 6: 12321237. [刘倩纯, 余潮, 张杰等. 鄱阳湖水体水质变化特征分析. 农业环境科学学报, 2013, 6: 1232-1237.]

[28] Mo MH, Fang SW, Song YJ et al. Water quality assessment and its changing characteristics research for the three stations in Poyang Lake. Journal of Water Resources and Water Engineering, 2012, 23(4): 90-94. [莫明浩, 方少文, 宋月君等. 鄱阳湖湖区三站点水质评价及其变化特征研究. 水资源与水工程学报, 2012, 23(4): 90-94. ]

[29] Xie L, Yang H, Qu XX et al. Dissolved organic matter release of Zizania caduciflora and Phragmites australis from Lake Dianchi. Environmental Science, 2013, 34(9):3458-3466. [谢理, 杨浩, 渠晓霞等. 滇池优势挺水植物荠草和芦苇 降解过程中 DOM 释放特征研究. 环境科学, 2013, 34(9): 3458-3466.]

[30] Wu HT, Lv XG, Yang Q et al. The early-stage litter decomposition and its influencing factors in the wetland of Sanjiang Plian, China. Acta Ecological Sinica, 2007, 27(10): 4027-4035. [武海涛, 吕宪国, 杨青等. 三江平原典型湿地枯落 物早期分解过程及影响因素. 生态学报, 2007, 27(10): 4027-4035.]

[31] Balasubramanian D, Arunachalam K, Das AK et al. Decomposition and nutrient release of Eichhornia crassipes, (mart.) solms. under different trophic conditions in wetlands of eastern himalayan foothills. Ecological Engineering, 2012, 44 (44) : 111-122.

[32] Fonseca AL, Bianchini I, Pimenta CM et al. The flow velocity as driving force for decomposition of leaves and twigs. Hydro- 
biologia, 2013, 703: 59-67.

[33] Wang WQ, Wang C, Liu BG. Effect of salinity on carbon, nitrogen and phosphorus stoichiometry during the decomposition of wetland litter. China Environmental Science, 2012, 32(9): 1683-1687. [王维奇, 王纯, 刘白贵. 盐度对湿地枯落物 分解过程中碳氮磷化学计量比的影响. 中国环境科学, 2012, 32(9) : 1683-1687.]

[34] Yoon TK, Noh NJ, Han S et al. Soil moisture effects on leaf litter decomposition and soil carbon dioxide efflux in wetland and upland forests. Soil Science Society of America Journal, 2014, 78(5) : 1804-1816.

[35] Tian J, Shu C, Chen H et al. Response of archaeal communities to water regimes under simulated warming and drought conditions in tibetan plateau wetlands. Journal of Soils and Sediments, 2015, 15(1): 179-188.

[36] Jonsson A, Meili M, Bergström AK et al. Whole-lake mineralization of allochthonous and autochthonous organic carbon in a large humic lake (örträsket, N. Sweden). Limnology and Oceanography, 2001, 46(7) : 1691-1700.

[37] Kim B, Choi K, Kim C et al. Effects of the summer monsoon on the distribution and loading of organic carbon in a deep reservoir, Lake Soyang, Korea. Water Research, 2000, 34(14) : 3495-3504.

[38] Lei XM, Duan HL, Liu WF et al. Soil nutrients and stoichiometry along elevation gradients in shallow-lakes of Poyang Lake Wetland. Soils, 2017, 49(1) : 40-48. [雷学明, 段洪浪, 刘文飞等. 鄱阳湖湿地碟形湖泊沿高程梯度土壤养分 及化学计量研究. 土壤, 2017, 49(1): 40-48.]

[39] Yan YP, Qian HY, Zhou YM et al. The effects of vegetation restoration on water quality in the degraded wetlands of Poyang Lake. Ecology and Environmental Science, 2010, 19(9): 2136-2141. [严玉平, 钱海燕, 周杨明等. 鄱阳湖双退区 受损湿地植被恢复对水质的影响. 生态环境学报, 2010, 19(9) : 2136-2141.] 